\title{
Parathyroidectomy versus cinacalcet in the treatment of tertiary hyperparathyroidism after kidney transplantation: a retrospective study
}

\author{
Suyun Jung ${ }^{1}$, Hyosang $\mathrm{Kim}^{1}$, Hyunwook Kwon ${ }^{2}$, Sung Shin ${ }^{2}$, Young Hoon Kim², Won Woong Kim², \\ Tae-Yon Sung ${ }^{2}$, Yu-Mi Lee ${ }^{2}$, Ki-Wook Chung ${ }^{2}$, Su-Kil Park ${ }^{1}$, Chung Hee Baek ${ }^{1}$ \\ ${ }^{1}$ Department of Internal Medicine, Asan Medical Center, University of Ulsan College of Medicine, Seoul, Republic of Korea \\ 2Department of Surgery, Asan Medical Center, University of Ulsan College of Medicine, Seoul, Republic of Korea
}

\begin{abstract}
Background: Hyperparathyroidism is common in patients with chronic kidney disease with reduced renal function and has been observed after kidney transplantation. The optimal treatment for cases in which hyperparathyroidism persists after kidney transplantation has not been determined.

Methods: This retrospective study included 83 patients with tertiary hyperparathyroidism who underwent kidney transplantation between 2000 and 2018 at a single tertiary center in Korea. Sixty-four patients underwent parathyroidectomy and 19 patients were treated with cinacalcet following renal transplantation. Biochemical parameters and clinical outcomes were compared between the two groups.

Results: Serum calcium and parathyroid hormone (PTH) levels improved in both the parathyroidectomy and cinacalcet groups. One year after treatment, parathyroidectomy resulted in a lower mean serum calcium level than cinacalcet $(9.7 \pm 0.7 \mathrm{mg} / \mathrm{dL}$ vs. $10.5 \pm$ $0.7 \mathrm{mg} / \mathrm{dL}, \mathrm{p}=0.001)$. Regarding serum PTH, the parathyroidectomy group showed a significantly lower PTH level than the cinacalcet group at 6 months $(129.1 \pm 80.3 \mathrm{pg} / \mathrm{mL}$ vs. $219.2 \pm 92.5 \mathrm{pg} / \mathrm{mL}, \mathrm{p}=0.002)$ and 1 year $(118.8 \pm 75.5 \mathrm{pg} / \mathrm{mL}$ vs. $250.6 \pm 94.5 \mathrm{pg} /$ $\mathrm{mL}, \mathrm{p}<0.001$ ). There was no statistically significant difference in the incidence of kidney transplant rejection, graft failure, cardiovascular events, fracture risk, or bone mineral density changes between the two groups.

Conclusion: Parathyroidectomy appears to reduce PTH and calcium levels effectively in tertiary hyperparathyroidism. However, creatinine level and allograft rejection should be monitored closely.
\end{abstract}

Keywords: Cinacalcet, Hyperparathyroidism, Kidney transplantation, Parathyroidectomy

\section{Introduction}

Secondary hyperparathyroidism, which increases the se- rum parathyroid hormone (PTH) level, is a phenomenon caused by decreased renal function in chronic kidney disease (CKD) [1]. A persistent increase in the serum PTH

Received: September 13, 2021; Revised: November 17, 2021; Accepted: December 10, 2021

Correspondence: Chung Hee Baek

Department of Internal Medicine, Asan Medical Center, University of Ulsan College of Medicine, 88 Olympic-ro 43-gil, Songpa-gu, Seoul 05505, Republic of Korea. E-mail:bch393@gmail.com

ORCID: https://orcid.org/0000-0001-7611-2373

Copyright (C) 2022 by The Korean Society of Nephrology

(a) This is an Open Access article distributed under the terms of the Creative Commons Attribution Non-Commercial and No Derivatives License (http:// creativecommons.org/licenses/by-nc-nd/4.0/) which permits unrestricted non-commercial use, distribution of the material without any modifications, and reproduction in any medium, provided the original works properly cited. 
level is associated with CKD-mineral bone disease, soft tissue and vascular calcification, and cardiovascular disease (CVD); as a result, it reportedly increases the mortality rate of patients [2].

Secondary hyperparathyroidism usually shows improvement after successful kidney transplantation (KT) [3]. Nevertheless, hyperparathyroidism has been observed to persist for up to 1 year after KT in more than $25 \%$ of patients. Tertiary hyperparathyroidism refers to the persistence of high serum PTH levels after KT [3,4].

Following tertiary hyperparathyroidism associated with hypercalcemia and hypophosphatemia, the risks of renal allograft dysfunction, graft failure, osteoporosis, and bone fracture increase [5-8]. Persistent hypercalcemia after transplantation causes various problems. According to a study, hypercalcemia can threaten graft function, and the incidence of CVD was noted to increase as the corrected calcium level rose [7]. A study of large cohorts derived from the Assessment of Lescol in Renal Transplantation trial reported that posttransplant persistent hyperparathyroidism is an independent risk factor for renal graft loss and all-cause mortality [9]. A longitudinal study showed that persistent hyperparathyroidism after KT increases the risk of fracture. Other research concurs that the hypophosphatemia associated with KT can induce osteomalacia and increase the risk of fracture $[8,10,11]$.

Medical treatment with cinacalcet or surgical treatment with parathyroidectomy (PTX) are both viable options for addressing tertiary hyperparathyroidism [12]. Cinacalcet is a calcimimetic drug that suppresses the production of PTH by enhancing the sensitivity of the calcium-sensing receptors of the parathyroid gland to calcium [13]. This drug has been reported to be effective in reducing calcium and PTH levels after KT [14-16]. The other axis of treatment, PTX, is generally performed when hypercalcemia that does not respond to medical treatment persists [17]. PTH and serum calcium levels are significantly reduced after PTX; however, the long-term effect of this treatment has not been well-studied [18]. In addition, some studies have reported that renal graft function is impaired after PTX $[19,20]$.

Since the introduction of cinacalcet, few studies have compared its efficacy to that of PTX. Therefore, there is still debate as to which treatment is better. Most of the studies that compared the efficacies of these treatments were retrospective investigations with short follow-up periods [21-25]. The only existing prospective randomized controlled trial had a small sample size [26]. There is a paucity of data available, especially from Korea; thus, this study sought to compare the efficacies of cinacalcet and PTX in patients with tertiary hyperparathyroidism of a single center in Korea.

\section{Methods}

\section{Study design and population}

This study was performed in accordance with the Declaration of Helsinki. It was approved by the Institutional Review Board of Asan Medical Center (No. 2020-0774), and written informed consent was waived due to its restrospective nature.

This retrospective cohort study initially included $178 \mathrm{pa}-$ tients who either took cinacalcet or underwent PTX after KT between 2000 and 2018 at a tertiary medical center in Korea. The inclusion criteria were persistent PTH elevation ( $>65 \mathrm{pg} / \mathrm{mL}$ ) with hypercalcemia (>10.5 mg/dL) after KT and an age of at least 19 years at the time of KT. Among the 178 patients, cases with missing or insufficient follow-up data were excluded. In addition, patients who underwent PTX or took cinacalcet after starting dialysis for end-stage renal disease (ESRD) after KT were excluded. Finally, 83 patients were evaluated altogether.

\section{Outcomes}

The biochemical outcomes were serum PTH, calcium, phosphorus, creatinine levels, and estimated glomerular filtration rate (eGFR) at 3 and 6 months and 1, 2, and 3 years after the start of treatment or surgery. The clinical outcomes were the incidence of graft rejection, graft failure, cardiovascular events, fracture, and bone mineral density (BMD) between the PTX group and the cinacalcet group.

\section{Data collection}

We collected patient data through electronic charts. Patient baseline characteristics included age, sex, etiology of ESRD, dialysis type before KT, and the duration of dialysis. 
KT-related data included the type of KT, ABO incompatibility, human leukocyte antigen (HLA) mismatch, and HLA-sensitization. HLA-sensitized KT was defined as a case in which at least one of the following characteristics was present: B-cell flow cytometry crossmatch, T-cell flow cytometry crossmatch, and complement-dependent cytotoxicity crossmatch. PTX-related data included laboratory data until 3 years after PTX (PTH, albumin-corrected calcium, phosphorus, creatinine, and eGFR), indication of PTX, complications, and medication(s) before PTX. PTH levels were measured using a second-generation assay (Nichols Institute Diagnostics, San Juan Capistrano, CA, USA). The eGFR used the Modification of Diet in Renal Disease equation. Cinacalcet (Regpara; Kyowa Hakko Kirin Co., Ltd.,Tokyo, Japan) administration group data also included laboratory data until 3 years after treatment.

\section{Treatment of tertiary hyperparathyroidism}

Cinacalcet was administered at an average dose of $25 \mathrm{mg}$ per day. Subtotal PTX was performed in 58 patients (90.6\%) and total PTX was performed in six patients (9.4\%). We discussed the advantages, disadvantages, and costs of the two treatments with patients having persistently elevated PTH ( $>65 \mathrm{pg} / \mathrm{mL}$ ) and hypercalcemia $(>10.5 \mathrm{mg} / \mathrm{dL})$ after KT and considered surgical treatment. The immunosuppressive drugs utilized were calcineurin inhibitors (tacrolimus or cyclosporine), corticosteroids (prednisolone or methylprednisolone), and antimetabolites (mycophenolate or azathioprine).

\section{Statistical analysis}

Statistical analyses were conducted using R (version 3.5.1; R Foundation for Statistical Computing, Vienna, Austria; http:// www.R.project.org) and GraphPad Prism version 5.0 (GraphPad Software, San Diego, CA, USA; http://www. graphpad.com). Continuous variables were presented as mean \pm standard deviation values and categorical variables were presented as frequencies (percentages). We used the $t$ test to compare continuous variables and the chi-square test or Fisher exact test to compare categorical variables. A p-value of less than 0.05 was considered statistically significant.

\section{Results}

\section{Study population}

From 2000 to 2018, a total of 178 patients underwent PTX or took cinacalcet from among those who underwent KT. Among the 178 patients, nine patients under the age of 19 years, 46 patients with missing or insufficient follow-up data, and 40 patients who underwent treatment with ESRD after failed KT were excluded (Fig. 1). We identified 83 patients who had tertiary hyperparathyroidism and met all the selection criteria. Nineteen patients were included in the cinacalcet group and 64 patients were included in the PTX group.

\section{Baseline characteristics}

Baseline characteristics of the patients in both groups at the time of KT are shown in Table 1. The mean age of patients in the cinacalcet group ( $45.7 \pm 7.4$ years) was lower than that of patients in the PTX group (50.2 \pm 8.6 years, $p$ $=0.04$ ). Considering dialysis duration before KT, the mean duration for patients in the cinacalcet group was shorter

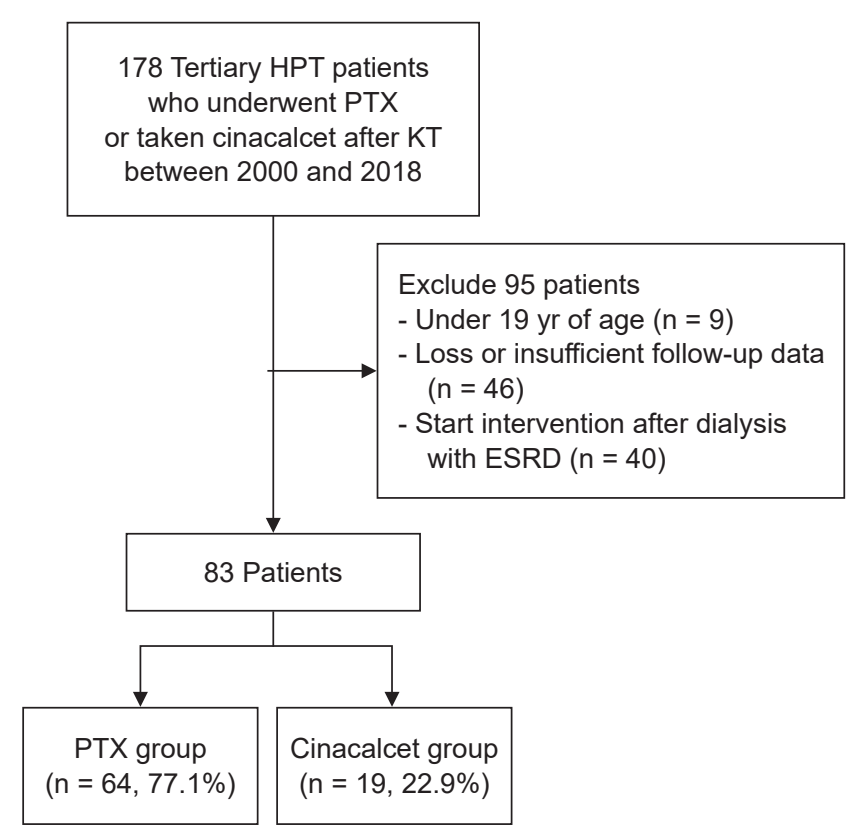

Figure 1. Flowchart of the selection process of the study participants.

ESRD, end-stage renal disease; HPT, hyperparathyroidism; KT, kidney transplantation; PTX, parathyroidectomy. 
Table 1. Baseline characteristics

\begin{tabular}{|c|c|c|c|}
\hline Characteristic & $\begin{array}{l}\text { Cinacalcet } \\
\text { group }\end{array}$ & $\begin{array}{l}\text { Parathyroidec- } \\
\text { tomy group }\end{array}$ & p-value \\
\hline No. of patients & 19 & 64 & \\
\hline Age (yr) & $45.7 \pm 7.4$ & $50.2 \pm 8.6$ & 0.04 \\
\hline Sex & & & 0.61 \\
\hline Male & $12(63.2)$ & 34 (53.1) & \\
\hline Female & $7(36.8)$ & 30 (46.9) & \\
\hline Body mass index $\left(\mathrm{kg} / \mathrm{m}^{2}\right)$ & $22.5 \pm 3.1$ & $22.3 \pm 2.8$ & 0.78 \\
\hline Etiology of ESRD & & & 0.59 \\
\hline Hypertension & $7(36.8)$ & 23 (35.9) & \\
\hline Diabetes & $2(10.5)$ & $3(4.7)$ & \\
\hline Glomerulonephritis & $6(31.6)$ & $16(25.0)$ & \\
\hline Others & $4(21.1)$ & $22(34.4)$ & \\
\hline Dialysis type & & & $>0.99$ \\
\hline Hemodialysis & $15(78.9)$ & $51(79.7)$ & \\
\hline Peritoneal dialysis & $4(21.1)$ & $13(20.3)$ & \\
\hline Dialysis duration (yr) & $8.1 \pm 3.7$ & $11.2 \pm 5.1$ & 0.01 \\
\hline \multicolumn{4}{|l|}{ Baseline lab data before KT } \\
\hline Corrected calcium (mg/dL) & $10.0 \pm 1.0$ & $10.3 \pm 1.0$ & 0.30 \\
\hline Phosphorus (mg/dL) & $5.9 \pm 1.9$ & $5.8 \pm 1.3$ & 0.72 \\
\hline $\begin{array}{l}\text { Parathyroid hormone } \\
(\mathrm{pg} / \mathrm{mL})\end{array}$ & $702.1 \pm 511.9$ & $761.4 \pm 606.1$ & 0.70 \\
\hline No. of transplants received & & & 0.55 \\
\hline 1 & $16(84.2)$ & $59(92.2)$ & \\
\hline 2 & $3(15.8)$ & $5(7.8)$ & \\
\hline Donor age (yr) & $50.7 \pm 8.6$ & $46.6 \pm 12.8$ & 0.19 \\
\hline Donor sex & & & $>0.99$ \\
\hline Male & $13(68.4)$ & $45(70.3)$ & \\
\hline Female & $6(31.6)$ & $19(29.7)$ & \\
\hline Type of KT & & & 0.56 \\
\hline Living-donor & 7 (36.8) & $17(26.6)$ & \\
\hline Deceased-donor & $12(63.2)$ & $47(73.4)$ & \\
\hline ABO incompatibility of KT & & & 0.92 \\
\hline ABO-compatible & $18(94.7)$ & $58(90.6)$ & \\
\hline ABO incompatible & $1(5.3)$ & $6(9.4)$ & \\
\hline HLA mismatch & & & 0.29 \\
\hline $0-3$ & $11(57.9)$ & $26(40.6)$ & \\
\hline $4-6$ & $8(42.1)$ & $38(59.4)$ & \\
\hline HLA-sensitized KT & & & $>0.99$ \\
\hline Non-sensitized & $19(100)$ & $62(96.9)$ & \\
\hline Sensitized & $0(0)$ & $2(3.1)$ & \\
\hline $\begin{array}{l}\text { Time interval between KT } \\
\text { and treatment (mo) }\end{array}$ & $23.1 \pm 29.9$ & $23.2 \pm 22.6$ & 0.99 \\
\hline
\end{tabular}

Data are expressed as number only, mean \pm standard deviation, or number (\%).

ESRD, end-stage renal disease; HLA, human leukocyte antigen; KT, kidney transplantation.
Table 2. The characteristics of PTX group

\begin{tabular}{ll}
\hline Characteristic & PTX group $(n=64)$ \\
\hline Complication of PTX & $2(3.1)$ \\
Hematoma & $2(3.1)$ \\
Postoperative hypocalcemia & $0(0)$ \\
Recurrent laryngeal nerve injury & \\
Medication before PTX & $50(78.1)$ \\
None & $14(21.9)$ \\
Vitamin D analog & $0(0)$ \\
Cinacalcet &
\end{tabular}

Data are expressed as number (\%).

PTX, parathyroidectomy.

than that of patients in the PTX group $(8.1 \pm 3.7$ years vs. $11.2 \pm 5.1$ years, $p=0.01$ ). There were no differences in other baseline characteristics. Among all cases of KT, the kidneys were obtained from deceased donors in $71.1 \%$ cases, $91.6 \%$ of the recipients were ABO-compatible, and $97.6 \%$ of the cases were non-sensitized KT. The mean time from KT to PTX in 64 patients was $23.2 \pm 22.6$ months, and the mean time from KT to cinacalcet administration in 19 patients was $23.1 \pm 29.9$ months $(\mathrm{p}=0.99)$.

Details of the PTX group are summarized in Table 2. Complications occurred in four of 64 patients (6.3\%), with half of these complications being hematoma and the remaining half being postoperative hypocalcemia. No recurrent laryngeal nerve injury occurred in any of the study participants. Before PTX, 50 of 64 patients $(78.1 \%)$ were not taking medications for hyperparathyroidism, while 14 (21.9\%) were taking vitamin D analogs. After PTX, half of the patients were given vitamin $\mathrm{D}$ or calcium to prevent hypocalcemia or hungry bone syndrome.

\section{Biochemical outcomes}

Posttreatment laboratory values are presented in Table 3. There was no significant difference in serum-corrected calcium levels between the two groups before treatment ( $p$ $=0.20$ ); however, these values were higher in the cinacalcet group throughout the follow-up period at 6 months $(\mathrm{p}<0.001), 1$ year $(\mathrm{p}=0.001)$, and 3 years $(\mathrm{p}=0.002)$ after the start of treatment. Although normocalcemia was not achieved in the cinacalcet group, it was achieved and maintained from three months after surgery in the PTX group. Both groups showed a trend of decreasing calcium levels 
Table 3. Biochemical outcomes: laboratory data during the follow-up period

\begin{tabular}{|c|c|c|c|}
\hline Variable & $\begin{array}{l}\text { Cinacalcet group } \\
\qquad(\mathrm{n}=19)\end{array}$ & $\begin{array}{l}\text { Parathyroidectomy } \\
\text { group }(n=64)\end{array}$ & p-value \\
\hline \multicolumn{4}{|c|}{ Corrected calcium (mg/dL) } \\
\hline Pretreament & $11.0 \pm 0.8$ & $11.3 \pm 0.8$ & 0.20 \\
\hline $3 \mathrm{Mo}$ & $10.6 \pm 0.9$ & $9.4 \pm 0.9$ & $<0.001$ \\
\hline $6 \mathrm{Mo}$ & $10.6 \pm 0.7$ & $9.5 \pm 0.7$ & $<0.001$ \\
\hline $1 \mathrm{Yr}$ & $10.5 \pm 0.7$ & $9.7 \pm 0.7$ & 0.001 \\
\hline $2 Y r$ & $10.8 \pm 1.0$ & $9.3 \pm 0.5$ & 0.001 \\
\hline $3 \mathrm{Yr}$ & $10.9 \pm 0.7$ & $9.4 \pm 0.9$ & 0.002 \\
\hline \multicolumn{4}{|c|}{ Parathyroid hormone (pg/mL) } \\
\hline Pretreament & $267.9 \pm 118.5$ & $334.7 \pm 240.0$ & 0.15 \\
\hline $3 \mathrm{Mo}$ & $225.8 \pm 91.3$ & $124.8 \pm 75.4$ & $<0.001$ \\
\hline $6 \mathrm{Mo}$ & $219.2 \pm 92.5$ & $129.1 \pm 80.3$ & 0.002 \\
\hline $1 Y r$ & $250.6 \pm 94.5$ & $118.8 \pm 75.5$ & $<0.001$ \\
\hline $2 \mathrm{Yr}$ & $247.7 \pm 88.2$ & $102.0 \pm 41.1$ & $<0.001$ \\
\hline $3 \mathrm{Yr}$ & $205.6 \pm 103.3$ & $107.8 \pm 71.2$ & 0.03 \\
\hline \multicolumn{4}{|c|}{ Phosphorus (mg/dL) } \\
\hline Pretreament & $2.5 \pm 0.6$ & $2.4 \pm 0.4$ & 0.51 \\
\hline $3 \mathrm{Mo}$ & $2.6 \pm 0.6$ & $3.0 \pm 0.7$ & 0.08 \\
\hline $6 \mathrm{Mo}$ & $2.8 \pm 0.4$ & $3.0 \pm 0.7$ & 0.23 \\
\hline $1 Y r$ & $2.6 \pm 0.5$ & $2.9 \pm 0.6$ & 0.11 \\
\hline $2 \mathrm{Yr}$ & $2.6 \pm 0.7$ & $2.9 \pm 0.5$ & 0.31 \\
\hline $3 \mathrm{Yr}$ & $2.5 \pm 0.4$ & $3.1 \pm 0.7$ & 0.06 \\
\hline \multicolumn{4}{|c|}{ Creatinine (mg/dL) } \\
\hline Pretreament & $1.0 \pm 0.3$ & $1.0 \pm 0.3$ & 0.96 \\
\hline $3 \mathrm{Mo}$ & $1.0 \pm 0.2$ & $1.3 \pm 1.0$ & 0.03 \\
\hline $6 \mathrm{Mo}$ & $1.0 \pm 0.2$ & $1.3 \pm 1.2$ & 0.22 \\
\hline $1 Y r$ & $1.0 \pm 0.3$ & $1.3 \pm 1.2$ & 0.30 \\
\hline $2 \mathrm{Yr}$ & $1.1 \pm 0.3$ & $1.1 \pm 0.3$ & 0.99 \\
\hline $3 \mathrm{Yr}$ & $0.9 \pm 0.2$ & $1.6 \pm 2.0$ & 0.22 \\
\hline \multicolumn{4}{|c|}{$\operatorname{eGFR}\left(\mathrm{mL} / \mathrm{min} / 1.73 \mathrm{~m}^{2}\right)$} \\
\hline Pretreament & $78.0 \pm 26.3$ & $71.9 \pm 21.0$ & 0.33 \\
\hline $3 \mathrm{Mo}$ & $75.3 \pm 20.2$ & $63.3 \pm 21.6$ & 0.08 \\
\hline $6 \mathrm{Mo}$ & $80.1 \pm 20.1$ & $69.2 \pm 21.0$ & 0.12 \\
\hline $1 \mathrm{Yr}$ & $75.9 \pm 27.8$ & $69.9 \pm 23.6$ & 0.46 \\
\hline $2 \mathrm{Yr}$ & $76.5 \pm 27.2$ & $72.4 \pm 19.9$ & 0.67 \\
\hline $3 \mathrm{Yr}$ & $84.7 \pm 25.0$ & $60.9 \pm 27.9$ & 0.11 \\
\hline \multicolumn{4}{|l|}{$\Delta \operatorname{eGFR}(\%)^{\mathrm{a}}$} \\
\hline $3 \mathrm{Mo}$ & $-4.1 \pm 25.8$ & $-15.6 \pm 27.1$ & 0.19 \\
\hline $6 \mathrm{Mo}$ & $6.3 \pm 22.5$ & $-15.7 \pm 22.0$ & 0.008 \\
\hline $1 \mathrm{Yr}$ & $6.5 \pm 22.0$ & $-6.0 \pm 28.4$ & 0.18 \\
\hline $2 Y r$ & $1.1 \pm 20.5$ & $-9.1 \pm 32.0$ & 0.43 \\
\hline $3 \mathrm{Yr}$ & $1.8 \pm 24.8$ & $-4.4 \pm 34.7$ & 0.73 \\
\hline
\end{tabular}

Data are expressed as mean \pm standard deviation.

eGFR, estimated glomerular filtration rate; KT, kidney transplantation.

${ }^{a}$ The delta eGFR ( $\triangle$ eGFR, \%) was calculated as the difference between the current eGFR and baseline eGFR [100 × (current eGFR - baseline eGFR)/ baseline eGFR]. after treatment compared to those before treatment. The mean serum PTH level was lower in the cinacalcet group than in the PTX group before treatment $(267.9 \pm 118.5 \mathrm{pg} /$ $\mathrm{mL}$ vs. $334.7 \pm 240.0 \mathrm{pg} / \mathrm{mL}, \mathrm{p}=0.15$ ). Following the initiation of treatment, PTH levels in the cinacalcet group were higher than the PTH group at all follow-up visits, i.e., at 6 months $(\mathrm{p}=0.002), 1$ year $(\mathrm{p}<0.001)$, and 3 years $(\mathrm{p}=0.03)$. The phosphorus levels did not differ significantly between the groups. Creatinine levels were significantly higher in the PTX group than in the cinacalcet group at three months after treatment ( $\mathrm{p}=0.03)$; however, this difference was not significant thereafter. No significant difference was found in the eGFR values between the two groups. Because the baseline eGFR values of the two groups were different, delta eGFR analysis was further performed to compensate for this difference. At 6 months after intervention, the delta eGFR was higher in the cinacalcet group than in the PTX group $(6.3 \% \pm 22.5 \%$ vs. $-15.7 \% \pm 22.0 \%, p=0.008)$. Despite the lack of significance, the delta eGFR value in the PTX group was continuously negative. Short-term laboratory data collected within 1 month after PTX are presented in Supplementary Fig. 1 (available online).

\section{Clinical outcomes}

The rejection, graft failure, cardiovascular event, and fracture rates of the two groups are presented in Table 4. Rejection occurred in 11 of 64 patients $(17.2 \%)$ in the PTX group but none of the patients in the cinacalcet group; however, the difference in the occurrence of rejection between the

Table 4. Clinical outcomes after management of tertiary hyperparathyroidism

\begin{tabular}{lccc}
\hline Variable & $\begin{array}{c}\text { Cinacalcet group } \\
(\mathrm{n}=19)\end{array}$ & $\begin{array}{c}\text { Parathyroidectomy } \\
\text { group }(\mathrm{n}=64)\end{array}$ & p-value \\
\hline Rejection & & $53(82.8)$ & 0.06 \\
$\quad$ None & $19(100)$ & $11(17.2)$ & \\
$\geq 1$ time & $0(0)$ & $3(4.7)$ & $>0.99$ \\
Graft failure & $1(5.3)$ & & $>0.99$ \\
Cardiovascular event & $18(94.7)$ & $2(3.1)$ & \\
$\quad$ None & $1(5.3)$ & & 0.55 \\
$\geq 1$ time & & $62(96.9)$ & \\
Fracture & $18(94.7)$ & $2(3.1)$ & \\
$\quad$ None & $1(5.3)$ & & \\
$\geq 1$ time & & & \\
\hline
\end{tabular}

Values are expressed as frequency (\%). 
two groups was not statistically significant $(p=0.06)$. There were no statistically significant differences between the two groups in terms of the rates of graft failure, cardiovascular events, and fracture. The incidence rates of fracture during follow-up were $5.3 \%(\mathrm{n}=1)$ and $3.1 \%(\mathrm{n}=2)$ in the cinacalcet and PTX groups $(\mathrm{p}=0.55)$, respectively. In all three cases, steroids were administered after transplantation. According to Kaplan-Meier curve analysis, renal transplant allograft survival was not statistically significant $(\mathrm{p}=0.77)$ (Fig. 2). In both groups, no significant difference was found in the change in BMD between the pretreatment and posttreatment periods (Table 5).

\section{Discussion}

In this retrospective cohort study, serum calcium and PTH levels decreased in both the PTX and cinacalcet groups.

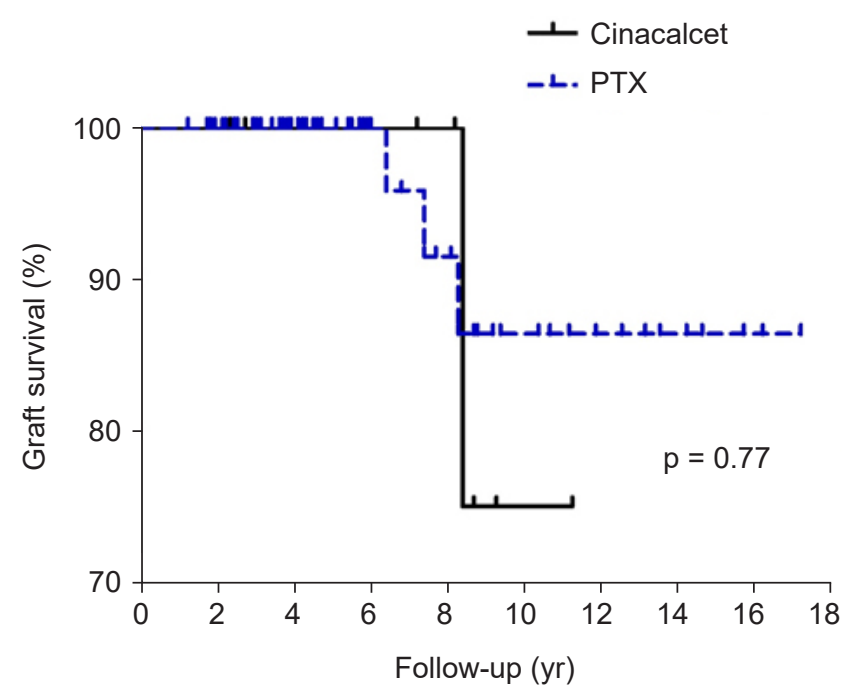

Figure 2. Kaplan-Meier curve of the renal transplant graft survival.

PTX, parathyroidectomy.

Table 5. Changes in BMD between before and after treatment

\begin{tabular}{lccc}
\hline T-score change & $\begin{array}{c}\text { Cinacalcet } \\
\text { group }(\mathrm{n}=3)\end{array}$ & $\begin{array}{c}\text { Parathyroidectomy } \\
\text { group }(\mathrm{n}=21)\end{array}$ & p-value \\
\hline Lumbar spine & $0.4 \pm 1.0$ & $0.3 \pm 0.7$ & 0.97 \\
Femur total & $-0.2 \pm 0.2$ & $0.1 \pm 0.6$ & 0.42 \\
Femur neck & $-0.2 \pm 0.3$ & $0.0 \pm 0.7$ & 0.49 \\
\hline
\end{tabular}

BMD was evaluated in 24 patients whose pre- and post-BMD data were available.

$\mathrm{BMD}$, bone mineral density.
Serum calcium level was maintained within normal range from three months after PTX. The cinacalcet group showed the lowest serum calcium levels at 1 year after administration compared to that before administration but did not demonstrate normocalcemia during the follow-up period. Renal function showed higher serum creatinine levels in the PTX group at three months after treatment; however, these levels were maintained thereafter without a statistically significant difference between the two groups. In the analysis performed by delta eGFR, the PTX group showed a significant decrease in eGFR compared to the cinacalcet group at 6 months after treatment. The rate of rejection was higher in the PTX group; however, there was no significant difference in the rate of graft survival between the groups. The rates of CVD and fracture events did not differ between the two groups.

Surgical treatment of tertiary hyperparathyroidism was more effective than the administration of cinacalcet in correcting hypercalcemia and lowering PTH levels. Similar findings were confirmed in several other studies [22,23,27]. A randomized controlled trial compared surgical treatment with cinacalcet in two cohorts of 15 patients with normocalcemia at 12 months as the primary endpoint. In comparison with $67 \%$ of patients treated with cinacalcet, $100 \%$ of patients achieved normocalcemia after PTX [26].

There are several concerns about surgical treatment. One of them is the rate of postoperative complications. In this study, postoperative complications occurred in only $6 \%$ of the participants, and all of these complications were temporary. In another study, Finnerty et al. [23] reported that complications, all of which were temporary, occurred in eight patients (24\%). Another concern is the deterioration of graft function following PTX. Although the cause is unclear, the mechanism is a rapid decrease in serum PTH levels after PTX reduces renal perfusion, which results in renal function impairment. Because PTH has a favorable influence on hemodynamics in terms of the glomerular filtration rate and renal blood flow, this deterioration of renal graft function is likely caused by the resultant relative hypoparathyroidism that occurs after PTX [19,20,28]. Therefore, Littbarski et al. [29] suggested that PTX should be performed at least 1 year after KT to improve long-term outcomes. In our study, the mean time-lapse from KT to PTX in 64 patients was $23.2 \pm 22.6$ months. Sixteen of 64 patients underwent surgery within 1 year after KT, and two 
of them experienced acute rejection.

With regard to graft outcome, although there was no graft rejection in the cinacalcet group, it occurred in 11 patients $(17.2 \%)$ in the PTX group. Although no significant difference was observed in the rate of graft rejection between the two groups $(p=0.06)$, the cinacalcet group included a small number of patients; thus, it was difficult to conclude about the lack of significant difference. There was no significant difference in the rates of graft failure between the two groups. A 5-year follow-up study revealed that there was no significant difference in kidney function between the two groups [30]. Although our study did not show any significant results with respect to the graft outcome between the two groups, other studies have reported the existence of such differences $[23,26]$. One retrospective review revealed that the overall rate of transplant allograft failure was lower in the PTX cohort (9\% vs. $33 \%, \mathrm{p}=0.007$ ) [23]. A randomized controlled trial by Cruzado et al. [26] found that both groups experienced a 12-month decline in eGFR, although the cinacalcet group experienced a more severe decline than the PTX group. However, there were no rejection episodes to account for this result. To date, there remains a paucity of studies demonstrating the differences between the two groups in the rates of graft outcome; therefore, further research is needed.

In the case of cinacalcet, the Evaluation of Cinacalcet Hydrochloride Therapy to Lower Cardiovascular Events trial revealed that it does not significantly reduce the rate of major CVD events compared to the placebo in patients with secondary hyperparathyroidism who were undergoing hemodialysis [31]. However, studies on the effects of cinacalcet on CVD events in patients with tertiary hyperparathyroidism remain lacking. PTX was associated with a decreased incidence of significant CVD events after surgery in patients with secondary hyperparathyroidism [32,33]. In a study comparing the effects of PTX and cinacalcet in secondary hyperparathyroidism, PTX decreased the risk of new CVD events by $86 \%$ compared to cinacalcet [34]. In our study, there was no significant difference in the incidence of CVD events between the two groups. Because there are few studies comparing the rates of CVD events in both groups undergoing treatment for tertiary hyperparathyroidism, more studies are needed in the future.

Tertiary hyperparathyroidism is associated with an increased risk of osteoporosis and a major risk of fractures
$[8,10]$. PTX and cinacalcet lower the risk of fracture in secondary hyperparathyroidism $[35,36]$. PTX, which was effective for controlling tertiary hyperparathyroidism, improved BMD 12 months after surgery, whereas cinacalcet did not [26]. In a randomized trial conducted among patients who underwent KT, although cinacalcet improved the biochemical parameters, there was no significant improvement in $\mathrm{BMD}$ in the cinacalcet group compared to the placebo group [37]. It is not yet clear whether PTX and cinacalcet lower the fracture risk in KT patients with tertiary hyperparathyroidism. In our study, three patients experienced fractures; however, there was no statistically significant difference in the incidence of fractures between the two groups.

This study had several limitations. First, it was a retrospective study conducted at a single center, which means there is a possibility of selection bias. Second, because of its small sample size, definitive conclusions cannot be drawn, which is the case in many studies on tertiary hyperparathyroidism. Despite the large number of KTs conducted at our medical center, we were only able to identify 83 patients who met the selection criteria for this study over a period of 18 years. To overcome these limitations, our study included patients with a longer follow-up duration than that found in previously reported retrospective studies. Third, in Korea, the use of cinacalcet in KT is not covered by insurance; thus, a sufficient dose to normalize serum calcium and PTH may not have been administered in some cases. Fourth, regarding the BMD results, there was difficulty in deriving significant results because the data of only very few patients were available from both before and after treatment. For future studies, we are currently planning to set up a protocol to measure BMD before and after treatment.

In conclusion, PTX appears to lower PTH and calcium levels effectively in tertiary hyperparathyroidism. However, creatinine level and allograft rejection should be monitored closely. More prospective randomized studies are warranted to determine the appropriate first-line therapy in patients with tertiary hyperparathyroidism based on clinical outcomes.

\section{Conflicts of interest}

All authors have no conflicts of interest to declare. 


\section{Funding}

This study was supported by a grant (2019IT0009) from the Asan Institute for Life Sciences, Asan Medical Center, Seoul, Korea.

\section{Acknowledgments}

The authors would like to thank Hyojin Lee for coordinating kidney transplantation at our medical center and Sujin Lee for supporting research.

\section{Authors' contributions}

Conceptualization: $\mathrm{CHB}$

Formal analysis: $\mathrm{CHB}, \mathrm{SJ}$

Investigation: SJ

Resources: All authors

Supervision: CHB, H Kim, H Kwon, SS, YHK, WWK, TYS, YML, KWC, SKP

Writing-original draft: $\mathrm{CHB}$, SJ

Writing-review \& editing: CHB,H Kim, H Kwon, SS, YHK, WWK, TYS, YML, KWC, SKP

All authors read and approved the final manuscript.

\section{ORCID}

Suyun Jung, https://orcid.org/0000-0002-3444-5724

Hyosang Kim, https://orcid.org/0000-0001-8140-9534

Hyunwook Kwon, https://orcid.org/0000-0001-5018-5304

Sung Shin, https://orcid.org/0000-0001-7318-4208

Young Hoon Kim, https://orcid.org/0000-0003-3840-8426

Won Woong Kim, https://orcid.org/0000-0003-3471-2068

Tae-Yon Sung, https://orcid.org/0000-0002-2179-6269

Yu-Mi Lee, https://orcid.org/0000-0002-8183-2604

Ki-Wook Chung, https://orcid.org/0000-0002-4418-1857

Su-Kil Park, https://orcid.org/0000-0001-7242-7204

Chung Hee Baek, https://orcid.org/0000-0001-7611-2373

\section{References}

1. Cunningham J, Locatelli F, Rodriguez M. Secondary hyperparathyroidism: pathogenesis, disease progression, and therapeutic options. Clin J Am Soc Nephrol 2011;6:913-921.

2. Fraser WD. Hyperparathyroidism. Lancet 2009;374:145-158.
3. Gioviale MC, Bellavia M, Damiano G, Lo Monte AI. Post-transplantation tertiary hyperparathyroidism. Ann Transplant 2012;17:111-119.

4. Evenepoel P, Claes K, Kuypers D, Maes B, Bammens B, Vanrenterghem Y. Natural history of parathyroid function and calcium metabolism after kidney transplantation: a single-centre study. Nephrol Dial Transplant 2004;19:1281-1287.

5. Borchhardt K, Sulzbacher I, Benesch T, Födinger M, Sunder-Plassmann G, Haas M. Low-turnover bone disease in hypercalcemic hyperparathyroidism after kidney transplantation. Am J Transplant 2007;7:2515-2521.

6. Brandenburg VM, Floege J. Transplantation: an end to bone disease after renal transplantation? Nat Rev Nephrol 2013;9:5-6.

7. Ozdemir FN, Afsar B, Akgul A, Usluoğullari C, Akçay A, Haberal M. Persistent hypercalcemia is a significant risk factor for graft dysfunction in renal transplantation recipients. Transplant Proc 2006;38:480-482.

8. Perrin P, Caillard S, Javier RM, et al. Persistent hyperparathyroidism is a major risk factor for fractures in the five years after kidney transplantation. Am J Transplant 2013;13:2653-2663.

9. Pihlstrøm H, Dahle DO, Mjøen G, et al. Increased risk of all-cause mortality and renal graft loss in stable renal transplant recipients with hyperparathyroidism. Transplantation 2015;99:351-359.

10. Bouquegneau A, Salam S, Delanaye P, Eastell R, Khwaja A. Bone disease after kidney transplantation. Clin J Am Soc Nephrol 2016;11:1282-1296.

11. Jeon HJ, Kim H, Yang J. Bone disease in post-transplant patients. Curr Opin Endocrinol Diabetes Obes 2015;22:452-458.

12. Douthat WG, Chiurchiu CR, Massari PU. New options for the management of hyperparathyroidism after renal transplantation. World J Transplant 2012;2:41-45.

13. Brown EM. Clinical utility of calcimimetics targeting the extracellular calcium-sensing receptor (CaSR). Biochem Pharmacol 2010;80:297-307.

14. Cohen JB, Gordon CE, Balk EM, Francis JM. Cinacalcet for the treatment of hyperparathyroidism in kidney transplant recipients: a systematic review and meta-analysis. Transplantation 2012;94:1041-1048.

15. Jo HA, Han KH, So YK, Jun H, Han SY. Effect of cinacalcet in kidney transplant patients with hyperparathyroidism. Transplant Proc 2019;51:1397-1401.

16. Szwarc I, Argilés A, Garrigue V, et al. Cinacalcet chloride is efficient and safe in renal transplant recipients with posttransplant hyperparathyroidism. Transplantation 2006;82:675-680. 
17. Jeon HJ, Kim YJ, Kwon HY, et al. Impact of parathyroidectomy on allograft outcomes in kidney transplantation. Transpl Int 2012;25:1248-1256.

18. Copley JB, Wüthrich RP. Therapeutic management of postkidney transplant hyperparathyroidism. Clin Transplant 2011;25:24-39.

19. Garcia A, Mazuecos A, Garcia T, González P, Ceballos M, Rivero M. Effect of parathyroidectomy on renal graft function. Transplant Proc 2005;37:1459-1461.

20. Schwarz A, Rustien G, Merkel S, Radermacher J, Haller H. Decreased renal transplant function after parathyroidectomy. Nephrol Dial Transplant 2007;22:584-591.

21. Dulfer RR, Franssen GJ, Hesselink DA, Hoorn EJ, van Eijck $\mathrm{CH}$, van Ginhoven TM. Systematic review of surgical and medical treatment for tertiary hyperparathyroidism. Br J Surg 2017;104:804-813.

22. Dulfer RR, Koh EY, van der Plas WY, et al. Parathyroidectomy versus cinacalcet for tertiary hyperparathyroidism; a retrospective analysis. Langenbecks Arch Surg 2019;404:71-79.

23. Finnerty BM, Chan TW, Jones G, et al. Parathyroidectomy versus cinacalcet in the management of tertiary hyperparathyroidism: surgery improves renal transplant allograft survival. Surgery 2019;165:129-134.

24. Rivelli GG, Lima ML, Mazzali M. Therapy for persistent hypercalcemic hyperparathyroidism post-renal transplant: cinacalcet versus parathyroidectomy. J Bras Nefrol 2020;42:315-322.

25. Soliman AR, Maamoun HA, Soliman MA, Darwish H, Elbanna E. Cinacalcet versus parathyroidectomy in the treatment of secondary hyperparathyroidism post renal transplantation. Rom J Intern Med 2016;54:184-189.

26. Cruzado JM, Moreno P, Torregrosa JV, et al. A randomized study comparing parathyroidectomy with cinacalcet for treating hypercalcemia in kidney allograft recipients with hyperparathyroidism. J Am Soc Nephrol 2016;27:2487-2494.

27. Yang RL, Freeman K, Reinke CE, et al. Tertiary hyperparathyroidism in kidney transplant recipients: characteristics of patients selected for different treatment strategies. Transplantation
2012;94:70-76.

28. Wolzt M, Schmetterer L, Dorner G, et al. Hemodynamic effects of parathyroid hormone-related peptide-(1-34) in humans. J Clin Endocrinol Metab 1997;82:2548-2551.

29. Littbarski SA, Kaltenborn A, Gwiasda J, et al. Timing of parathyroidectomy in kidney transplant candidates with secondary hyperparathryroidism: effect of pretransplant versus early or late post-transplant parathyroidectomy. Surgery 2018;163:373-380.

30. Moreno P, Coloma A, Torregrosa JV, et al. Long-term results of a randomized study comparing parathyroidectomy with cinacalcet for treating tertiary hyperparathyroidism. Clin Transplant 2020;34:e13988.

31. EVOLVE Trial Investigators, Chertow GM, Block GA, et al. Effect of cinacalcet on cardiovascular disease in patients undergoing dialysis. N Engl J Med 2012;367:2482-2494.

32. Costa-Hong V, Jorgetti V, Gowdak LH, Moyses RM, Krieger EM, De Lima JJ. Parathyroidectomy reduces cardiovascular events and mortality in renal hyperparathyroidism. Surgery 2007;142:699-703.

33. Lorenz K, Bartsch DK, Sancho JJ, Guigard S, Triponez F. Surgical management of secondary hyperparathyroidism in chronic kidney disease: a consensus report of the European Society of Endocrine Surgeons. Langenbecks Arch Surg 2015;400:907-927.

34. Kim WW, Rhee Y, Kim BS, et al. Clinical outcomes of parathyroidectomy versus cinacalcet in the clinical management of secondary hyperparathyroidism. Endocr J 2019;66:881-889.

35. Moe SM, Abdalla S, Chertow GM, et al. Effects of cinacalcet on fracture events in patients receiving hemodialysis: the EVOLVE Trial. J Am Soc Nephrol 2015;26:1466-1475.

36. Rudser KD, de Boer IH, Dooley A, Young B, Kestenbaum B. Fracture risk after parathyroidectomy among chronic hemodialysis patients. J Am Soc Nephrol 2007;18:2401-2407.

37. Evenepoel P, Cooper K, Holdaas H, et al. A randomized study evaluating cinacalcet to treat hypercalcemia in renal transplant recipients with persistent hyperparathyroidism. Am J Transplant 2014;14:2545-2555. 